\title{
Spondyloperipheral dysplasia-short ulna syndrome
}

INSERM

\section{Source}

INSERM. (1999). Orphanet: an online rare disease and orphan drug data base. Spondyloperipheral dysplasia-short ulna syndrome. ORPHA:1856

Spondyloperipheral dysplasia-short ulna syndrome is a rare, genetic, primary bone dysplasia, with highly variable phenotype, typically characterized by platyspondyly, brachydactyly type E changes (short metacarpals and metatarsals, short distal phalanges in hands and feet), bilateral short ulnae and mild short stature. Other reported features include additional skeletal findings (e.g. midface hypoplasia, degenerative changes in proximal femora, limited elbow extension, bilateral sacralization of L5, clubfeet), as well as myopia, hearing loss, and intellectual disability. 